\title{
Treatment challenges for community oncologists treating postmenopausal women with endocrine- resistant, hormone receptor-positive, human epidermal growth factor receptor 2-negative advanced breast cancer
}

This article was published in the following Dove Press journal:

Cancer Management and Research

II July 2016

Number of times this article has been viewed

\section{William J Gradishar}

Division of Hematology/Oncology, Department of Medicine, Northwestern University Feinberg School of Medicine, Chicago, IL, USA
Correspondence: William J Gradishar Northwestern University Feinberg School of Medicine, NMH/Arkes Family Pavilion Suite 850, 676 N Saint Clair, Chicago, IL 60611 , USA

Tel + I 3126956I80

Email w-gradishar@northwestern.edu

\begin{abstract}
Community-based oncologists are faced with challenges and opportunities when delivering quality patient care, including high patient volumes and diminished resources; however, there may be the potential to deliver increased patient education and subsequently improve outcomes. This review discusses the treatment of postmenopausal women with endocrine-resistant, hormone receptor-positive, human epidermal growth factor receptor 2-negative advanced breast cancer in order to illustrate considerations in the provision of pertinent quality education in the treatment of these patients and the management of therapy-related adverse events. An overview of endocrine-resistant breast cancer and subsequent treatment challenges is also provided. Approved treatment options for endocrine-resistant breast cancer include hormonal therapies and mammalian target of rapamycin inhibitors. Compounds under clinical investigation are also discussed.
\end{abstract}

Keywords: community oncologists, hormone receptor-positive advanced breast cancer, endocrine resistance

\section{Introduction}

Endocrine therapy is the standard of care for women with hormone receptor (HR)positive advanced breast cancer. In postmenopausal women, endocrine therapies include nonsteroidal and steroidal aromatase inhibitors, selective estrogen receptor (ER) modulators, ER downregulators, progestin, androgens, and high-dose estrogen. ${ }^{1}$ Aromatase inhibitors are the preferred endocrine therapy for first-line and adjuvant treatment of postmenopausal women, ${ }^{1,2}$ while first-line tamoxifen therapy is commonly used because of its demonstrated efficacy in lowering the risk of recurrence and improving clinical outcomes. ${ }^{2-5}$

For patients with advanced disease, the therapeutic options are increasingly complex. ${ }^{1}$ For instance, the increased use of aromatase inhibitors in the adjuvant setting suggests that many patients with recurrent disease may no longer be candidates for aromatase inhibitor therapy. ${ }^{6}$ Individualized treatment that accounts for disease- and patient-related factors is recommended, but real-life clinical circumstances, which may include cost, availability, and experience with particular therapies, should also be considered. . $^{2,4,7}$ 
Interpreting clinical trial results and subsequent clinical extrapolation can be challenging because of changing patterns of adjuvant hormone therapy use and increasing availability of treatment options. ${ }^{2,8}$ Many women with advanced breast cancer also do not fit the profile of those who participate in clinical trials, making it sometimes difficult to extrapolate clinical trial data into routine clinical practice. ${ }^{7}$ Additionally, there is often a lack of evidence to support the personalized treatment of patients with advanced breast cancer; hence, therapeutic decisions are often based on clinical experience and instinct. ${ }^{2,9}$

Compared with academic centers, community practices deliver a disproportionately large share of patient care, with small- and medium-sized practices seeing more than onethird of new patients ${ }^{10}$; oncologists in community practices see almost twice as many patients and spend more time on clinical care than those in academic centers. ${ }^{11}$ In community practices, higher patient volumes may be attributed in part to community-based oncologists caring for patients with a variety of cancers, ${ }^{10-12}$ while oncologists in academic practices spend significantly more time focusing on the treatment of one specific cancer type than oncologists in smaller practices. ${ }^{11}$ In addition, community practices often utilize a purely incentive-based model of compensation and serve as major points of enrollment for clinical trials of novel anticancer therapies. ${ }^{10,11}$ However, financial and resource constraints within community-based oncology practices ${ }^{13,14}$ may hinder their ability to implement expensive technologies, obtain resources for proper patient care, and enable access to current therapies and clinical trials. ${ }^{10,14,15}$ These challenges may be overcome through collaboration with hospitals, which will require standardization of treatment approaches and adherence to evidence-based clinical decision-making. ${ }^{13}$

For community-based oncologists, delivering quality patient care involves both challenges and opportunities. While being confronted with high patient volumes and decreased resources, these oncologists may have the opportunity to deliver increased education regarding treatment and subsequently improve outcomes. Oncologists must remain up to date on current standards of care and therapies and understand the information needs of patients, based on both the patients' individual circumstances and the chosen therapy.

This review focuses on the treatment of postmenopausal women with endocrine-resistant, HR-positive, human epidermal growth factor receptor 2 (HER2)-negative advanced breast cancer. Particular consideration will be given to the provision of pertinent quality education on the treatment and therapy-related adverse events (AEs) for these patients.

\section{Overview of endocrine resistance}

The management of endocrine-resistant breast cancer is a significant clinical need ${ }^{16}$ because most patients either do not respond to initial endocrine therapy or have disease progression or recurrence during treatment. ${ }^{17,18}$ It is estimated that $\sim 30 \%$ of patients with metastatic breast cancer regress with initial endocrine therapy and another $20 \%$ have prolonged stable disease, ${ }^{19}$ response duration to subsequent therapies correspondingly decreases, ${ }^{20}$ and all patients with metastatic disease ultimately become refractory to endocrine therapy. ${ }^{5}$ Therefore, the appropriate management of these patients by community-based oncologists will require an understanding of the mechanisms involved in the development of endocrine resistance.

Multiple mechanisms for endocrine resistance have been proposed, including deregulation of the ER signaling pathway via loss of estrogen receptor alpha $(E R \alpha)$ expression, mutations in ER $\alpha$, or altered expression of ER coregulators; alterations in cell cycle and cell survival signaling; increased expression of growth factor receptors, such as epidermal growth factor receptor (EGFR), HER2, and insulin-like growth factor 1 receptor; and activation of alternate survival pathways, such as the mitogen-activated protein kinase, nuclear factor $\kappa \mathrm{B}(\mathrm{NF}-\kappa \mathrm{B})$, or phosphatidylinositol-3 kinase $(\mathrm{PI} 3 \mathrm{~K}) / \mathrm{mammalian}$ target of rapamycin (mTOR) pathways. ${ }^{18,21}$

\section{Treatment options for endocrine- resistant breast cancer}

To ensure the delivery of quality patient care, oncologists in the community practice setting must remain up to date on current standards of care and therapies. Furthermore, it is essential for community-based oncologists to be aware of novel agents that are currently in clinical development given that community practices are often major points of recruitment for clinical trials. Current strategies to address endocrine resistance include therapies targeting pathways associated with endocrine resistance, combination therapy, and agents that are not dependent on HR expression. ${ }^{5,21-25}$ In postmenopausal patients with HR-positive, HER2-negative endocrine-resistant advanced breast cancer, fulvestrant (250 $\mathrm{mg}$ and $500 \mathrm{mg}$ ) and everolimus $(10 \mathrm{mg} / \mathrm{d})$ in combination with exemestane $(25 \mathrm{mg} / \mathrm{d})$ are the only licensed therapies indicated for patients with disease progression 
following prior hormonal therapy. ${ }^{26,27}$ Several agents are also undergoing clinical investigation in this setting.

\section{Fulvestrant}

Fulvestrant is a selective ER downregulator commonly used as second- or later-line therapy for patients with resistance to other endocrine therapies. ${ }^{9}$ Fulvestrant $(250 \mathrm{mg}$ ) was shown in a combined analysis of two Phase III clinical trials to be at least as effective as anastrozole in postmenopausal women with advanced breast cancer who had progressed on previous adjuvant or first-line endocrine therapy, which was generally tamoxifen. ${ }^{28}$ No significant differences across predefined covariates in the consistency of treatment effect were found, including age, number of prior hormonal therapies, receptor status, visceral involvement, presence of measurable disease, and sensitivity to aromatase inhibitor therapy. ${ }^{28}$ The subsequently reported Phase III CONFIRM trial, which compared fulvestrant $500 \mathrm{mg}$ versus $250 \mathrm{mg}$ in patients who experienced progression on prior endocrine therapy, indicated that the 500-mg dose may be more effective because it was associated with a significant increase in progressionfree survival (PFS) versus the 250-mg dose (6.5 months vs 5.5 months; hazard ratio [HR], $0.80 ; 95 \%$ confidence interval [CI], 0.68-094; $P=0.006) .{ }^{29}$ At the final exploratory overall survival (OS) analysis, which occurred when $75 \%$ of patients had died, the median OS for the 500-mg and 250-mg groups was 26.4 months and 22.3 months, respectively (HR, 0.81 ; 95\% CI, 0.69-0.96; $P=0.02) .{ }^{30}$ The overall treatment effect at this final OS analysis was consistent across predefined covariables, which included baseline age, response to last endocrine therapy received before fulvestrant, receptor status at diagnosis, baseline visceral disease, last therapy before fulvestrant, and measurable disease at baseline. ${ }^{30}$

\section{Everolimus}

Current guidelines recommend the addition of the mTOR inhibitor everolimus to the steroidal aromatase inhibitor exemestane as a treatment consideration in women with HR-positive, HER2-negative advanced breast cancer who have disease progression or recurrence on prior nonsteroidal aromatase inhibitor (NSAI) treatment. ${ }^{1}$ Approval for this therapy is based on the Phase III BOLERO-2 trial, in which everolimus in combination with exemestane was compared with exemestane monotherapy in women with HR-positive, HER2-negative advanced breast cancer who had disease progression or recurrence on prior NSAI treatment. ${ }^{31}$ Final study results with a median follow-up of 18 months confirmed that the addition of everolimus to exemestane significantly prolonged PFS compared with exemestane alone ( 7.8 months vs 3.2 months; HR, 0.45 ; 95\% CI, 0.38-0.54; $P<0.0001) .{ }^{32}$ OS results, a key secondary end point of the study, were numerically but not significantly greater with everolimus plus exemestane therapy versus placebo plus exemestane therapy (31.0 months vs 26.6 months; HR, 0.89; 95\% CI, $0.73-1.10 ; P=0.14) .{ }^{33}$

The beneficial effects of everolimus treatment in the BOLERO-2 trial were consistent across patient subgroups defined by baseline characteristics and prior therapy, ${ }^{32}$ including in patients who had received only adjuvant or neoadjuvant therapy as last therapy before study entry and received everolimus plus exemestane as first-line therapy (median PFS, 11.5 months vs 4.1 months); ${ }^{34}$ in patients who received chemotherapy for advanced breast cancer before entry into the trial (median PFS, 6.1 months vs 2.7 months); ${ }^{35}$ and in patients with or without visceral disease (median PFS, 6.8 months in women with visceral metastases treated with everolimus plus exemestane vs 2.8 months for those treated with exemestane monotherapy) and regardless of Eastern Cooperative Oncology Group performance status or the presence of bone-only lesions at baseline. ${ }^{36}$

\section{Treatments in development}

There are a number of agents in development in the setting of endocrine-resistant breast cancer that are targeting the PI3K/ Akt/mTOR pathway, as well as other supposed pathways and molecular sites of resistance (Table 1).

\section{$\mathrm{PI3K} / \mathrm{Akt} / \mathrm{mTOR}$ pathway inhibitors}

Alpelisib (BYL719), buparlisib (BKM120), and taselisib (GDC-0032), which are inhibitors of the PI3K/Akt/mTOR pathway, are undergoing clinical investigation in combination with endocrine therapy in HR-positive metastatic breast cancer. A Phase I trial of alpelisib in combination with everolimus with or without exemestane in a population that includes patients with advanced breast cancer is currently under way (NCT02077933). A Phase III trial of alpelisib plus fulvestrant is also under way and will include postmenopausal women with HR-positive, HER2-negative advanced breast cancer that has progressed on or after aromatase inhibitor therapy (NCT02437318). Buparlisib is being evaluated in two Phase III clinical trials in combination with fulvestrant in endocrine-resistant, HR-positive, HER2-negative advanced breast cancer in patients refractory to aromatase inhibitor therapy (NCT01610284) or after mTOR inhibitor 
Table I Overview of clinical trials in patients with endocrine-resistant breast cancer

\begin{tabular}{|c|c|c|c|c|}
\hline Agent & $\begin{array}{l}\text { Phase of } \\
\text { development }\end{array}$ & $\begin{array}{l}\text { Clinical trial } \\
\text { identifier }\end{array}$ & Status & Details \\
\hline \multicolumn{5}{|c|}{ PI3K/Akt/mTOR inhibitors } \\
\hline \multirow[t]{2}{*}{ Alpelisib (BYL7I9) } & 1 & NCT02077933 & Recruiting & $\begin{array}{l}\text { Safety and efficacy of alpelisib }+ \text { everolimus or alpelisib }+ \\
\text { everolimus }+ \text { exemestane in patients with advanced breas } \\
\text { cancer, renal cell cancer, and pancreatic tumors }\end{array}$ \\
\hline & III & NCT024373I8 & Recruiting & $\begin{array}{l}\text { Alpelisib + fulvestrant versus placebo + fulvestrant in } \\
\text { patients with HR+, HER2- advanced breast cancer who } \\
\text { progressed on or after aromatase inhibitor therapy }\end{array}$ \\
\hline \multirow[t]{2}{*}{ Buparlisib (BKMI20) } & III & $\begin{array}{l}\text { NCT0I6I0284 } \\
\text { (BELLE-2) }\end{array}$ & Completed & $\begin{array}{l}\text { BKMI } 20 \text { + fulvestrant versus placebo + fulvestrant } \\
\text { in postmenopausal women with HR+, HER2 - locally } \\
\text { advanced or metastatic breast cancer refractory to } \\
\text { aromatase inhibitors }\end{array}$ \\
\hline & III & $\begin{array}{l}\text { NCT0I633060 } \\
\text { (BELLE-3) }\end{array}$ & Recruiting & $\begin{array}{l}\text { BKMI } 20 \text { + fulvestrant versus placebo + fulvestrant in } \\
\text { postmenopausal women with HR+, HER2- aromatase- } \\
\text { inhibitor treated locally advanced or metastatic breast } \\
\text { cancer in patients who progressed on or after mTOR } \\
\text { inhibitor treatment }\end{array}$ \\
\hline Taselisib & III & $\begin{array}{l}\text { NCT0234022I } \\
\text { (SANDPIPER) }\end{array}$ & Recruiting & $\begin{array}{l}\text { Taselisib + fulvestrant versus placebo + fulvestrant } \\
\text { in postmenopausal women with HR+, HER2- locally } \\
\text { advanced or metastatic breast cancer who have disease } \\
\text { recurrence or progression during or after aromatase } \\
\text { inhibitor therapy }\end{array}$ \\
\hline
\end{tabular}

\section{HDAC inhibitors}

Exemestane + entinostat versus exemestane + placebo in postmenopausal women and men with recurrent $\mathrm{HR}+$, HER2 - locally advanced or metastatic breast cancer with disease progression on NSAl therapy in the metastatic setting or relapse while on or within 12 months of completing NSAI therapy

\section{CDK inhibitors}

Palbociclib (PD-033299I)

III

III

III

Ribociclib (LEEOII)
III

II

I/II

III

\section{NCT01740427 Ongoing (PALOMA-2) \\ NCT01942I35 Completed (PALOMA-3) \\ NCT02028507 Recruiting (PEARL)}

NCT0195802I Recruiting

NCT01919229 Completed

NCT01857193 Recruiting

NCT02422615 Recruiting
Palbociclib + letrozole versus placebo + letrozole for first-line treatment of postmenopausal women with ER+, HER2- advanced breast cancer

Palbociclib + fulvestrant versus placebo + fulvestrant in women of any menopausal status with HR+, HER2metastatic breast cancer after endocrine failure Palbociclib + exemestane versus capecitabine in $\mathrm{HR}+$, HER2 - metastatic breast cancer in postmenopausal women with resistance to NSAls

Ribociclib + letrozole versus placebo + letrozole as firstline therapy of HR+, HER2 - advanced breast cancer in postmenopausal women

Ribociclib (400 mg) + letrozole versus LEEOI I (600 mg) + letrozole in HR+, HER2-, grades 2-3 invasive breast cancer in postmenopausal women

Ribociclib + everolimus + exemestane versus LEEOI I + exemestane versus everolimus + exemestane in patients with ER+, HER2- advanced breast cancer Ribociclib $(600 \mathrm{mg})+$ fulvestrant versus placebo + fulvestrant in HR+/HER2 - advanced breast cancer who have received no or only one line of prior endocrine treatment 
Table I (Continued)

\begin{tabular}{|c|c|c|c|c|}
\hline Agent & $\begin{array}{l}\text { Phase of } \\
\text { development }\end{array}$ & $\begin{array}{l}\text { Clinical trial } \\
\text { identifier }\end{array}$ & Status & Details \\
\hline \multirow[t]{2}{*}{ Abemaciclib (LY2835219) } & III & $\begin{array}{l}\text { NCT0224662I } \\
\text { (MONARCH 3) }\end{array}$ & Ongoing & $\begin{array}{l}\text { Abemaciclib }(300 \mathrm{mg})+\text { letrozole or anastrozole versus } \\
\text { placebo + letrozole or anastrozole in HR+, HER2- locally } \\
\text { recurrent or metastatic breast cancer with no prior } \\
\text { systemic therapy }\end{array}$ \\
\hline & III & $\begin{array}{l}\text { NCT02I } 07703 \\
(\mathrm{MONARCH} 2)\end{array}$ & Ongoing & $\begin{array}{l}\text { Abemaciclib }(300 \mathrm{mg})+\text { fulvestrant versus placebo }+ \\
\text { fulvestrant in HR+, HER2 - locally advanced or metastatic } \\
\text { breast cancer }\end{array}$ \\
\hline \multicolumn{5}{|c|}{ Src-kinase pathway inhibitors } \\
\hline \multirow[t]{2}{*}{ Dasatinib } & II & NCT00696072 & Completed & $\begin{array}{l}\text { Letrozole }+ \text { dasatinib versus letrozole as first- and } \\
\text { second-line treatment for HR+, HER2- postmenopausal } \\
\text { patients with unresectable, locally recurrent or metastatic } \\
\text { breast cancer }\end{array}$ \\
\hline & II & NCT00754325 & & $\begin{array}{l}\text { Fulvestrant with or without dasatinib in men and } \\
\text { postmenopausal women who have hormone receptor- } \\
\text { positive advanced breast cancer previously treated with } \\
\text { an aromatase inhibitor }\end{array}$ \\
\hline \multicolumn{5}{|l|}{$\begin{array}{l}\text { NF-kB pathway and } \\
\text { proteasome inhibitors }\end{array}$} \\
\hline Bortezomib & II & NCTOII4240I & Ongoing & $\begin{array}{l}\text { Fulvestrant + bortezomib versus fulvestrant in } \\
\text { postmenopausal women with } E R+\text { locally advanced or } \\
\text { metastatic breast cancer resistant to aromatase inhibitors }\end{array}$ \\
\hline \multicolumn{5}{|l|}{ EGFR inhibitors } \\
\hline Erlotinib & II & NCT00570258 & Ongoing & $\begin{array}{l}\text { Fulvestrant }+ \text { erlotinib versus fulvestrant }+ \text { placebo in } \\
\text { postmenopausal women with } \mathrm{HR}+\text { metastatic breast } \\
\text { cancer who progressed on first-line hormonal therapy }\end{array}$ \\
\hline Vandetanib & II & $\begin{array}{l}\text { NCT008II369 } \\
\text { (ZAMBONEY) }\end{array}$ & $\begin{array}{l}\text { Completed } \\
\text { (no study results } \\
\text { reported) }\end{array}$ & $\begin{array}{l}\text { Fulvestrant }+ \text { vandetanib versus fulvestrant }+ \text { placebo in } \\
\text { postmenopausal women with bone predominant, HR+ } \\
\text { metastatic breast cancer }\end{array}$ \\
\hline
\end{tabular}

Abbreviations: CDK, cyclin-dependent kinase; EGFR, epidermal growth factor receptor; ER+, estrogen receptor-positive; HDAC, histone deacetylase; HER2-, human epidermal growth factor receptor 2-negative; HR+, hormone receptor-positive; mTOR, mammalian target of rapamycin; NSAI, nonsteroidal aromatase inhibitor.

pretreatment (NCT01633060). Finally, the combination of taselisib and fulvestrant is being evaluated in a Phase III trial of ER-positive, HER2-negative locally advanced or metastatic breast cancer that has recurred or progressed during or after aromatase inhibitor therapy (NCT02340221).

\section{Histone deacetylase inhibitors}

Entinostat is a histone deacetylase inhibitor that has been studied in a Phase II trial in combination with exemestane, which showed a trend for prolonged PFS versus exemestane alone in patients with HR-positive metastatic breast cancer progressing during NSAI therapy (4.3 months vs 2.3 months; HR, 0.73; $P=0.055)$; in an exploratory end point, patients receiving entinostat therapy showed improved median OS compared with those receiving exemestane alone (28.1 months vs 19.8 months; $P=0.036) .{ }^{37}$ A Phase III trial of entinostat plus exemestane in patients with recurrent
HR-positive advanced breast cancer who have relapsed or have progressive disease on prior NSAI therapy is under way (NCT02115282).

\section{Cyclin-dependent kinase inhibitors}

Palbociclib (PD-0332991) is a selective cyclin-dependent kinase (CDK) 4/6 inhibitor that was given accelerated US Food and Drug Administration approval in February 2015 for the treatment in combination with letrozole of postmenopausal women with ER-positive, HER2-negative metastatic breast cancer, ${ }^{38}$ based on results from a Phase II, randomized, multicenter trial in patients with advanced breast cancer. ${ }^{39}$ These results are currently being confirmed in a Phase III trial (PALOMA-2; NCT01740427).

For endocrine-resistant disease, palbociclib was evaluated in combination with fulvestrant in patients with metastatic disease after endocrine failure (PALOMA-3; 
NCT01942135) and in combination with exemestane (PEARL; NCT02028507). Recently, results from PALOMA-3 demonstrated that palbociclib plus fulvestrant had a significantly longer PFS versus fulvestrant alone (9.2 months vs 3.8 months; HR, 0.422; 95\% CI, 0.318-0.560; P<0.001). ${ }^{40}$ Ribociclib (LEE011) is another CDK 4/6 inhibitor that is currently under development in combination with letrozole (NCT01958021, NCT01919229), in combination with both everolimus and exemestane (NCT01857193), and in combination with fulvestrant (NCT02422615). Furthermore, ongoing Phase III trials are being conducted for a third CDK 4/6 inhibitor, abemaciclib (LY2835219), in combination with NSAI therapy (NCT02246621) or fulvestrant (NCT02107703).

\section{Src-kinase pathway inhibitors}

Dasatinib, an Src-kinase inhibitor, did not show a PFS benefit in combination with exemestane in a Phase II trial of patients with breast cancer resistant to NSAIs with a median PFS of 16 weeks in the placebo plus exemestane arm and 18 weeks in the dasatinib plus exemestane arm $(\mathrm{HR}, 0.86 ; P=0.148) .{ }^{41}$ Additional Phase II analyses have been completed with results pending (NCT00754325, NCT00696072).

\section{NF- $\kappa B$ pathway and proteasome inhibitors}

Bortezomib, a proteasome inhibitor that inhibits NF- $\kappa \mathrm{B}$ activation, is being studied in a Phase II trial in combination with fulvestrant (NCT01142401). However, previously reported Phase II trial results in combination with endocrine therapies in endocrine-resistant metastatic breast cancer did not demonstrate objective tumor responses with bortezomib therapy. ${ }^{42}$

\section{EGFR inhibitors}

The results for the EGFR inhibitor gefitinib in combination with endocrine therapy, which has been studied in a series of Phase II trials, have been inconclusive. ${ }^{43-46}$ Currently, erlotinib in combination with fulvestrant is being studied in a Phase II trial in patients with metastatic breast cancer progressing during first-line endocrine therapy (NCT00570258). Vandetanib, a novel tyrosine kinase inhibitor with activity against a number of receptor tyrosine kinases, including EGFR and vascular endothelial growth factor (VEGF) receptor, ${ }^{47}$ has been studied in a Phase II trial in combination with fulvestrant in patients with HR-positive metastatic breast cancer with predominant bone metastases after progression during prior endocrine therapy (NCT00811369). ${ }^{48}$ However, results indicate that the addition of vandetanib to fulvestrant did not improve PFS or OS in patients with bone metastases. $^{48}$

\section{VEGF receptor inhibitors}

Bevacizumab, a monoclonal antibody that prevents interaction between VEGF and its receptor, resulted in a median PFS of 17.1 months when used in combination with letrozole. ${ }^{49}$ Hormone therapy in combination with bevacizumab was assessed in a Phase II trial in postmenopausal women with newly diagnosed metastatic breast cancer who were intolerant to or had progressive disease while receiving an aromatase inhibitor. ${ }^{50}$ Anastrozole plus bevacizumab had a reported median time-to-progression of 21 months when used predominantly as first-line therapy, while fulvestrant plus bevacizumab had a median time-to-progression of 9 months when used as a second-line therapy. ${ }^{50}$ Bevacizumab plus endocrine therapy is currently being assessed as a first-line therapy in a Phase III trial (NCT00545077). ${ }^{51}$ However, the addition of bevacizumab to endocrine therapy in first-line treatment failed to produce a statistically significant increase in PFS or OS. ${ }^{51}$

\section{Patient education regarding AEs}

Educating patients on the identification and management of AEs associated with their treatment is vital for ensuring that they continue to take their medication for as long as it is beneficial. For community-based oncologists, who may be faced with diminished resources, it is also vital to educate patients on AE management. To illustrate, we will consider the management of AEs with aromatase inhibitors, tamoxifen, fulvestrant, mTOR inhibitors, and palbociclib.

\section{AEs associated with aromatase inhibitors and tamoxifen}

The most common acute effects of aromatase inhibitors are fatigue, back pain, dyspnea, headache, and hot flushes. ${ }^{52}$ Aromatase inhibitor therapy is also associated with bone-related AEs, particularly with long-term use, that include increased osteopenia, osteoporosis, and bone fracture risk; ${ }^{52}$ however, these AEs may be of less relevance in the metastatic setting given the patient's need for effective treatment. ${ }^{6}$ Hot flushes that accompany aromatase inhibitor therapy are common and can adversely affect quality of life. ${ }^{53-55}$ Musculoskeletal pain, joint pain, and stiffness are also commonly reported. ${ }^{56}$ Tamoxifen is typically well tolerated, and the most frequently reported AEs are hot flushes, fatigue, and nausea. ${ }^{52}$ Uterine bleeding, vaginal dryness or discharge, dyspareunia, loss of libido, and cataracts are reported less commonly, and deep 
vein thrombosis, venous thromboembolism, pulmonary embolism, and cardiovascular and ischemic cerebrovascular events are reported rarely. ${ }^{52}$

Previous studies have suggested that the management of vasomotor symptoms associated with hormonal therapy should include selective serotonin reuptake inhibitors, although their use with tamoxifen is not recommended because of the potential for negative drug-drug interactions. ${ }^{54,57-59}$ Gabapentin is an antiepileptic therapy that has been reported effective in managing vasomotor symptoms in patients with breast cancer, including those in whom selective serotonin reuptake inhibitors were ineffective. ${ }^{60}$ The evaluation of evidencebased treatment of hot flushes through a nurse-led clinic led to the development of a proposed algorithm for management that recommends a stepwise approach that includes lifestyle changes, reduction of risk factors, respiration and relaxation techniques, and subsequent escalation to pharmacological management, if required. ${ }^{61}$ Currently, no therapy has been demonstrated to effectively manage arthralgia associated with aromatase inhibitor therapy. ${ }^{54}$ The pharmacologic management of bone-related complications in patients with breast cancer is predominantly based on treating these complications in association with aging and osteoporosis. ${ }^{62}$ Postmenopausal women treated with adjuvant aromatase inhibitor therapy commonly receive calcium and vitamin D supplements, with bisphosphonate therapy available for those with osteopenia and monoclonal antibody therapy to increase bone mass in patients at high risk of fracture. ${ }^{63,64}$

\section{Fulvestrant-associated AEs}

Fulvestrant is an endocrine therapy, and AEs of interest have included those associated with its antiestrogenic effects. The most common AEs reported with fulvestrant are injectionsite pain, nausea, bone pain, and arthralgia. ${ }^{26}$ Results from a systematic review of Phase III trials in postmenopausal women with advanced breast cancer showed that the incidence of AEs was comparable between fulvestrant and other endocrine therapies. ${ }^{65}$ Fulvestrant demonstrated a lower incidence of joint disorders versus aromatase inhibitors and a lower incidence of hot flushes versus tamoxifen. ${ }^{52}$

\section{Everolimus-associated AEs}

\section{Stomatitis}

Stomatitis is inflammation of the mucous membranes of the mouth, including the oral cavity, inner surface of the lips, and the tongue, that is distinct from chemotherapyand radiotherapy-associated mucositis. ${ }^{66-68}$ Stomatitis can cause severe pain and may negatively affect quality of life by compromising the ability to eat, drink, and speak. Onset occurs early and is transient. ${ }^{67,69}$ In clinical trials, stomatitis developed in $44 \%-78 \%$ of everolimus-treated patients, with most events being grade 1 or $2 .{ }^{27}$

The management of stomatitis includes everolimus dose adjustments and discontinuations according to AE grade. ${ }^{27}$ Currently ongoing Phase II trials are assessing the use of dexamethasone mouthwash for the treatment of stomatitis and may provide additional evidence-based support for the appropriate prevention and/or management of this side effect when results are available (NCT02069093, NCT01698918).

\section{Noninfectious pneumonitis}

Noninfectious pneumonitis is a class effect of mTOR inhibitors involving noninfectious inflammation of the lungs ${ }^{66,70}$ that has been reported in up to $19 \%$ of patients treated with everolimus in clinical trials. ${ }^{27}$ If noninfectious pneumonitis occurs, everolimus dosing should be adjusted or discontinued according to severity. ${ }^{27}$

\section{Rash}

Rash is a class effect of mTOR inhibitors that typically manifests as acneiform dermatitis starting as an inflammatory lesion, with comedones occasionally appearing. ${ }^{71}$ Its distribution is wide and unusual, often appearing in areas not prone to acne, and onset occurs soon after treatment initiation. ${ }^{71}$ In clinical trials, $21 \%-59 \%$ of patients treated with everolimus experienced a rash, which was generally grade 1 or 2 in severity. ${ }^{27}$

\section{Infection}

Infection is considered a class effect of mTOR inhibitors because of its immunosuppressant properties, and it may include localized and systemic infections (eg, candidiasis, pneumonia, other bacterial infections, invasive fungal infections). ${ }^{71}$ The incidence rates of grades 3-4 infection with everolimus therapy were low, and infection was not reported as a major reason for dose adjustments or discontinuations across oncology indications. ${ }^{71}$

\section{Laboratory abnormalities}

Elevated serum creatinine, urinary protein, blood glucose, and lipids and decreases in hemoglobin, neutrophils, and platelets have been reported with everolimus therapy across oncology indications. ${ }^{27}$

\section{Palbociclib-associated AEs}

The most common AEs reported with palbociclib, the recently approved CDK 4/6 inhibitor, are neutropenia, leukopenia, 
fatigue, anemia, upper respiratory infection, and nausea. ${ }^{38}$ In clinical trials, neutropenia was the most frequently observed AE, with grades 3-4 events occurring in 54\%-62\% of palbociclib-treated patients ${ }^{39,40}$; however, the incidence of febrile neutropenia was low. ${ }^{40}$ Furthermore, higher incidence rates of infection have been reported in patients receiving palbociclib plus letrozole, compared with letrozole alone (34.2\% vs $24.4 \%$ ). In general, the management of some AEs associated with palbociclib includes patient monitoring and dose modifications, comprising interruptions or delays and/or dose reductions, or permanent discontinuation of palbociclib for grade 3 or $4 \mathrm{AEs}^{38}$

\section{Conclusion and perspectives}

The exposure of community-based oncologists to patients with HR-positive, HER2-negative advanced breast cancer is likely to increase given the high volume of patients treated at community practices. To provide ongoing quality care to these patients in the community-based oncology setting will require adequate knowledge of current treatment options and future novel therapies that are currently in development. Additionally, endocrine therapy options are expanding for patients with HR-positive, HER2-negative advanced breast cancer. As greater appreciation and understanding of endocrine resistance mechanisms have evolved, partnering endocrine therapy with novel targeted agents has been the focus of ongoing clinical research. To that end, the PI3K/mTOR signaling pathway has received a great deal of attention, and numerous agents that target this pathway are in clinical development. The mTOR inhibitor everolimus has been approved for the treatment of patients who develop disease progression following prior therapy with an NSAI. The CDK 4/6 inhibitor palbociclib was recently approved as first-line therapy in combination with an aromatase inhibitor.

The current trend to combine endocrine agents with targeted therapy has changed the toxicity profile that patients can experience. In some cases, this results in characteristic AEs more commonly associated with some chemotherapy drugs. As such, community-based clinicians must know how to best communicate expectations to patients regarding these new treatment strategies and employ the best means of managing AEs. By doing so, patient compliance and adherence can be optimized, thereby realizing the clinical benefits of these new treatment approaches.

\section{Acknowledgments}

Editorial support in the preparation of this manuscript was provided by Matthew Grzywacz (ApotheCom, Yardley, PA,
USA). This editorial support was funded by Novartis Pharmaceuticals Corporation.

\section{Disclosure}

Dr Gradishar has received research grants from the National Institute of Health and the Breast Cancer Research Foundation, and is a consultant for Pfizer and Eli Lilly. The author reports no other conflicts of interest in this work.

\section{References}

1. National Comprehensive Cancer Network Inc. NCCN Clinical Practice Guidelines in Oncology. Breast Cancer. Version 2. Fort Washington, PA: NCCN; 2015.

2. Cardoso F, Costa A, Norton L, et al. 1st International consensus guidelines for advanced breast cancer (ABC 1). Breast. 2012;21(3): 242-252.

3. Bonneterre J, Buzdar A, Nabholtz JM, et al; Arimidex Writing Committee; Investigators Committee Members. Anastrozole is superior to tamoxifen as first-line therapy in hormone receptor positive advanced breast carcinoma. Cancer. 2001;92(9):2247-2258.

4. Cardoso F, Harbeck N, Fallowfield L, Kyriakides S, Senkus E; ESMO Guidelines Working Group. Locally recurrent or metastatic breast cancer: ESMO Clinical Practice Guidelines for diagnosis, treatment and follow-up. Ann Oncol. 2012;23(suppl 7):vii11-vii19.

5. Harichand-Herdt S, Zelnak A, O'Regan R. Endocrine therapy for the treatment of postmenopausal women with breast cancer. Expert Rev Anticancer Ther. 2009;9(2):187-198.

6. McArthur HL, Morris PG. Aromatase inhibitor strategies in metastatic breast cancer. Int J Womens Health. 2010;1:67-72.

7. Palumbo R, Sottotetti F, Riccardi A, et al. Which patients with metastatic breast cancer benefit from subsequent lines of treatment? An update for clinicians. Ther Adv Med Oncol. 2013;5(6):334-350.

8. Wilson S, Chia SK. Treatment algorithms for hormone receptor-positive advanced breast cancer. Am Soc Clin Oncol Educ Book. 2013.

9. Cardoso F, Bischoff J, Brain E, et al. A review of the treatment of endocrine responsive metastatic breast cancer in postmenopausal women. Cancer Treat Rev. 2013;39(5):457-465.

10. American Society of Clinical Oncology. The state of cancer care in America, 2014: a report by the American Society of Clinical Oncology. J Oncol Pract. 2014;10(2):119-142.

11. Shanafelt TD, Gradishar WJ, Kosty M, et al. Burnout and career satisfaction among US oncologists. J Clin Oncol. 2014;32(7):678-686.

12. Desch CE, Blayney DW. Making the choice between academic oncology and community practice: the big picture and details about each career. J Clin Oncol. 2006;2:132-138.

13. Lippman AJ, Gallinson D, Johnstone D. Clinical practice issues in oncology impacted by healthcare reform. MD Advis. 2012;5(3):6-8.

14. Ullman K. Oncologist practice consolidation continues: driven by changes in reimbursement and standards of care, independent community oncology practices continue to dwindle. Am J Manag Care. 2012;18(5 Spec No):S236.

15. Tetreault SA, Harwin WN, Eagle D. 'Economies of scale' yield multiple benefits for a private, physician-run oncology practice. Oncology (Williston Park). 2013;27(7):616,618,C3.

16. Gnant M. Overcoming endocrine resistance in breast cancer: importance of mTOR inhibition. Expert Rev Anticancer Ther. 2012; 12(12):1579-1589.

17. Chang J, Fan W. Endocrine therapy resistance: current status, possible mechanisms and overcoming strategies. Anticancer Agents Med Chem. 2013;13(3):464-475.

18. Chlebowski RT. Strategies to overcome endocrine therapy resistance in hormone receptor-positive advanced breast cancer. Clin Invest. 2014;4:19-33. 
19. Osborne CK, Schiff R. Mechanisms of endocrine resistance in breast cancer. Annu Rev Med. 2011;62:233-247.

20. Chlebowski RT. Changing concepts of hormone receptor-positive advanced breast cancer therapy. Clin Breast Cancer. 2013;13(3): 159-166.

21. Garcia-Becerra R, Santos N, Diaz L, Camacho J. Mechanisms of resistance to endocrine therapy in breast cancer: focus on signaling pathways, miRNAs and genetically based resistance. Int $J$ Mol Sci. 2012;14(1):108-145.

22. Eroles P, Bosch A, Bermejo B, Lluch A. Mechanisms of resistance to hormonal treatment in breast cancer. Clin Transl Oncol. 2010; 12(4):246-252.

23. Xu Y, Sun Q. Headway in resistance to endocrine therapy in breast cancer. J Thorac Dis. 2010;2(3):171-177.

24. Tinoco G, Warsch S, Gluck S, Avancha K, Montero AJ. Treating breast cancer in the 21 st century: emerging biological therapies. $J$ Cancer. 2013;4(2):117-132.

25. Gluck S. Extending the clinical benefit of endocrine therapy for women with hormone receptor-positive metastatic breast cancer: differentiating mechanisms of action. Clin Breast Cancer. 2014;14(2):75-84.

26. Faslodex (fulvestrant) injection [package insert]. Wilmington, DE: AstraZeneca Pharmaceuticals LP; 2012.

27. Afinitor (everolimus) tablets for oral administration. Afinitor Disperz (everolimus tablets for oral suspension) [package insert]. East Hanover, NJ: Novartis Pharmaceuticals Corp; 2016.

28. Robertson JF, Osborne CK, Howell A, et al. Fulvestrant versus anastrozole for the treatment of advanced breast carcinoma in postmenopausal women: a prospective combined analysis of two multicenter trials Cancer. 2003;98(2):229-238.

29. di Leo A, Jerusalem G, Petruzelka L, et al. Results of the CONFIRM phase III trial comparing fulvestrant $250 \mathrm{mg}$ with fulvestrant $500 \mathrm{mg}$ in postmenopausal women with estrogen receptor-positive advanced breast cancer. J Clin Oncol. 2010;28(30):4594-4600.

30. di Leo A, Jerusalem G, Petruzelka L, et al. Final overall survival: fulvestrant $500 \mathrm{mg}$ vs $250 \mathrm{mg}$ in the randomized CONFIRM trial. J Natl Cancer Inst. 2014;106(1):djt337.

31. Baselga J, Campone M, Piccart M, et al. Everolimus in postmenopausal hormone receptor-positive advanced breast cancer. $N$ Engl J Med. 2012;366(6):520-529.

32. Yardley DA, Noguchi S, Pritchard KI, et al. Everolimus plus exemestane in postmenopausal patients with HR breast cancer: BOLERO-2 final progression-free survival analysis. Adv Ther. 2013;30(10): 870-884.

33. Piccart M, Hortobagyi GN, Campone M, et al. Everolimus plus exemestane for hormone-receptor-positive, human epidermal growth factor receptor-2-negative advanced breast cancer: overall survival results from BOLERO-2. Ann Oncol. 2014;25(12):2357-2362.

34. Beck JT, Hortobagyi GN, Campone M, et al. Everolimus plus exemestane as first-line therapy in HR, HER2 advanced breast cancer in BOLERO-2. Breast Cancer Res Treat. 2014;143(3):459-467.

35. Campone M, Lebrun F, Noguchi S, et al. Efficacy of everolimus plus exemestane in patients who received prior chemotherapy for advanced breast cancer or recurred after adjuvant endocrine therapy in BOLERO-2. Presented at: the American Society of Clinical Oncology Annual Meeting; May 31-June 4, 2013; Chicago, IL, USA.

36. Campone M, Bachelot T, Gnant M, et al. Effect of visceral metastases on the efficacy and safety of everolimus in postmenopausal women with advanced breast cancer: subgroup analysis from the BOLERO-2 study. Eur J Cancer. 2013;49(12):2621-2632.

37. Yardley DA, Ismail-Khan RR, Melichar B, et al. Randomized phase II, double-blind, placebo-controlled study of exemestane with or without entinostat in postmenopausal women with locally recurrent or metastatic estrogen receptor-positive breast cancer progressing on treatment with a nonsteroidal aromatase inhibitor. J Clin Oncol. 2013;31:2128-2135.

38. Ibrance (palbociclib) capsules, for oral use [package insert]. New York, NY: Pfizer Labs; 2015
39. Finn RS, Crown JP, Lang I, et al. The cyclin-dependent kinase $4 / 6$ inhibitor palbociclib in combination with letrozole versus letrozole alone as first-line treatment of oestrogen receptor-positive, HER2-negative, advanced breast cancer (PALOMA-1/TRIO-18): a randomised phase 2 study. Lancet Oncol. 2015;16(1):25-35.

40. Turner NC, Ro J, Andre F, et al. Palbociclib in hormone-receptor-positive advanced breast cancer. N Engl J Med. 2015;373(3):209-219.

41. Llombart A, Ravaioli A, Strauss L, et al. Randomized phase II study of dasatinib vs placebo in addition to exemestane in advanced ER/ PR-positive breast cancer [BMS CA180-261 Study]. Presented at: the San Antonio Breast Cancer Symposium; December 6-10, 2011; San Antonio, TX, USA.

42. Trinh XB, Sas L, Van Laere SJ, et al. A phase II study of the combination of endocrine treatment and bortezomib in patients with endocrine-resistant metastatic breast cancer. Oncol Rep. 2012;27(3): $657-663$.

43. Gutteridge E, Agrawal A, Nicholson R, Leung CK, Robertson J, Gee J. The effects of gefitinib in tamoxifen-resistant and hormoneinsensitive breast cancer: a phase II study. Int J Cancer. 2010;126(8): 1806-1816.

44. Carlson RW, O’Neill A, Vidaurre T, Gomez HL, Badve SS, Sledge GW. A randomized trial of combination anastrozole plus gefitinib and of combination fulvestrant plus gefitinib in the treatment of postmenopausal women with hormone receptor positive metastatic breast cancer. Breast Cancer Res Treat. 2012;133(3):1049-1056.

45. Cristofanilli M, Valero V, Mangalik A, et al. Phase II, randomized trial to compare anastrozole combined with gefitinib or placebo in postmenopausal women with hormone receptor-positive metastatic breast cancer. Clin Cancer Res. 2010;16(6):1904-1914.

46. Osborne CK, Neven P, Dirix LY, et al. Gefitinib or placebo in combination with tamoxifen in patients with hormone receptor-positive metastatic breast cancer: a randomized phase II study. Clin Cancer Res. 2011;17(5):1147-1159.

47. Siegfried JM, Gubish CT, Rothstein ME, Henry C, Stabile LP. Combining the multitargeted tyrosine kinase inhibitor vandetanib with the antiestrogen fulvestrant enhances its antitumor effect in non-small cell lung cancer. J Thorac Oncol. 2012;7(3):485-495.

48. Clemons MJ, Cochrane B, Pond GR, et al. Randomised, phase II, placebo-controlled, trial of fulvestrant plus vandetanib in postmenopausal women with bone only or bone predominant, hormone-receptorpositive metastatic breast cancer (MBC): the OCOG ZAMBONEY study. Breast Cancer Res Treat. 2014;146(1):153-162.

49. Traina TA, Rugo HS, Caravelli JF, et al. Feasibility trial of letrozole in combination with bevacizumab in patients with metastatic breast cancer J Clin Oncol. 2010;28(4):628-633.

50. Yardley DA, Burris HA 3rd, Clark BL, et al. Hormonal therapy plus bevacizumab in postmenopausal patients who have hormone receptorpositive metastatic breast cancer: a phase II Trial of the Sarah Cannon Oncology Research Consortium. Clin Breast Cancer. 2011;11(3): $146-152$.

51. Martin M, Loibl S, von Minckwitz MG, et al. Phase III trial evaluating the addition of bevacizumab to endocrine therapy as first-line treatment for advanced breast cancer: the letrozole/fulvestrant and avastin (LEA) study. J Clin Oncol. 2015;33(9):1045-1052.

52. Buijs C, de Vries EG, Mourits MJ, Willemse PH. The influence of endocrine treatments for breast cancer on health-related quality of life. Cancer Treat Rev. 2008;34(7):640-655.

53. Gibson LJ, Dawson CK, Lawrence DH, Bliss JM. Aromatase inhibitors for treatment of advanced breast cancer in postmenopausal women. Cochrane Database Syst Rev. 2009:CD003370.

54. Mortimer JE. Managing the toxicities of the aromatase inhibitors. Curr Opin Obstet Gynecol. 2010;22(1):56-60.

55. Fallowfield LJ, Bliss JM, Porter LS, et al. Quality of life in the intergroup exemestane study: a randomized trial of exemestane versus continued tamoxifen after 2 to 3 years of tamoxifen in postmenopausal women with primary breast cancer. J Clin Oncol. 2006;24(6): 910-917. 
56. Lonning P, Eikesdal HP. Aromatase inhibition 2013: clinical state of the art and questions that remain to be solved. Endocr Relat Cancer. 2013;20(4):R183-R201.

57. Loprinzi CL, Sloan JA, Perez EA, et al. Phase III evaluation of fluoxetine for treatment of hot flashes. J Clin Oncol. 2002;20(6):1578-1583.

58. Loprinzi CL, Sloan J, Stearns V, et al. Newer antidepressants and gabapentin for hot flashes: an individual patient pooled analysis. J Clin Oncol. 2009;27(17):2831-2837.

59. Stearns V, Beebe KL, Iyengar M, Dube E. Paroxetine controlled release in the treatment of menopausal hot flashes: a randomized controlled trial. JAMA. 2003;289(21):2827-2834.

60. Loprinzi CL, Kugler JW, Barton DL, et al. Phase III trial of gabapentin alone or in conjunction with an antidepressant in the management of hot flashes in women who have inadequate control with an antidepressant alone: NCCTG N03C5. J Clin Oncol. 2007;25(3):308-312.

61. Kligman L, Younus J. Management of hot flashes in women with breast cancer. Curr Oncol. 2010;17(1):81-86.

62. Gnant M. Role of bisphosphonates in postmenopausal women with breast cancer. Cancer Treat Rev. 2014;40(3):476-484.

63. Bosco D. Osteoporosis and aromatase inhibitors: experience and future prospects. Clin Cases Miner Bone Metab. 2012;9(2):89-91.

64. Prolia (denosumab) injection, for subcutaneous use [package insert]. Thousand Oaks, CA: Amgen Inc; 2015.
65. Flemming J, Madarnas Y, Franek JA. Fulvestrant for systemic therapy of locally advanced or metastatic breast cancer in postmenopausal women: a systematic review. Breast Cancer Res Treat. 2009;115(2): 255-268.

66. Porta C, Ostanto S, Ravaud A, et al. Management of adverse events associated with the use of everolimus in patients with advanced renal cell carcinoma. Eur J Cancer. 2011;47:1287-1298.

67. Pilotte AP, Hohos MB, Polson KM, Huftalen TM, Treister N. Managing stomatitis in patients treated with Mammalian target of rapamycin inhibitors. Clin J Oncol Nurs. 2011;15(5):E83-E89.

68. Eisen T, Sternberg CN, Robert C, et al. Targeted therapies for renal cell carcinoma: review of adverse event management strategies. J Natl Cancer Inst. 2012;104(2):93-113.

69. Rugo HS, Pritchard KI, Gnant M, et al. Incidence and time course of everolimus-related adverse events in postmenopausal women with hormone receptor-positive advanced breast cancer: insights from BOLERO-2. Ann Oncol. 2014;25(4):808-815.

70. White DA, Camus P, Endo M, et al. Noninfectious pneumonitis after everolimus therapy for advanced renal cell carcinoma. Am J Respir Crit Care Med. 2010;182(3):396-403.

71. Aapro M, Andre F, Blackwell K, et al. Adverse event management in patients with advanced cancer receiving oral everolimus: focus on breast cancer. Ann Nutr Metab. 2014;25(4):763-773.
Cancer Management and Research

\section{Publish your work in this journal}

Cancer Management and Research is an international, peer-reviewed open access journal focusing on cancer research and the optimal use of preventative and integrated treatment interventions to achieve improved outcomes, enhanced survival and quality of life for the cancer patient. The journal welcomes original research, clinical \& epidemiological

\section{Dovepress}

studies, reviews \& evaluations, guidelines, expert opinion \& commentary, case reports \& extended reports. The manuscript management system is completely online and includes a very quick and fair peerreview system, which is all easy to use. Visit http://www.dovepress.com/ testimonials.php to read real quotes from published authors. 